\title{
PENERAPAN KOMPRES KAYU MANIS (CINNAMOMUN BURMANI) TERHADAP NYERI PADA ASUHAN KEPERAWATAN GERONTIK DENGAN KASUS GOUT ARTHITIS
}

\author{
Application of Cinnamomun Burmani Against Pain in Gerontic Nursing Care with Gout Arthitis Case \\ Ni Made Ridla Nilasanti Parwata*,Tasnim, Dafrosia Darmi Manggasa, \\ Agusrianto, Desi Kristanti Dala \\ Poltekkes Kemenkes Palu \\ *Email korespondensi: ridlanilasanti.poltekkespalu@ gmail.com
}

\begin{abstract}
ABSTRAK
Pendahuluan: Gout Athitis merupakan penyakit metabolic yang di sebabkan oleh kelebihan kadar senyawa urat di dalam tubuh. Tahun 2017 jumlah penderita Gout Arthitis di Puskesmas Mapane sebanyak 613 penderita, tahun 2018 jumlah penderita meningkat menjadi 652 penderita. Jumlah tertinggi penderita terdapat di Kelurahan Kasiguncu sebanyak 22 penderita. Tujuan: Melakukan Asuhan Keperawatan Komprehensif dengan Penerapan Kompres Kayu Manis terhadap Penurunan Nyeri pada Asuhan Keperawatan Gerontik pasien Gout Arthitis. Metode: Observasional deskritif desain penelitian studi kasus. Hasil: Kompres kayu manis dapat nyeri gout Arthitis dari skala 6 menjadi 3 setelah 4 kali pemberian pada pagi hari selama 1 minggu dalam waktu 15-20 menit dapat menurunkan nyeri sendi akibat Gout Arthitis. Saran: diharapkan intervensi ini menjadi salah satu alternatif untuk mengurangi nyeri pada pasien dengan gout arthitis.
\end{abstract}

Kata Kunci: Gout; nyeri: kompres kayu manis

\section{ABSTRACT}

Introduction: Gout Athitis is a metabolic disease caused by excess levels of uric compounds in the body. In 2017, the number of sufferers of Gout Arthitis at Mapane Health Center was 613 patients, in 2018 the number of sufferers increased to 652 sufferers. The highest number of patients was found in Kasiguncu Village, with 22 patients. Usefull aim : Carry out Comprehensive Nursing Care with the Application of Cinnamon Compress to Reduce Pain in Gerontic Nursing Care for Gout Arthitis Patients. Method: Observational descriptive case study research design. Results: Cinnamon compress can reduce gout arthritis pain from a scale of 6 to 3 after 4 times of administration in the morning for 1 week within 15-20 minutes can reduce joint pain due to Gout Arthitis. It is hoped that this intervention will be an alternative to reduce pain in patients with gout arthitis.

Keywords: Gou; pain; cinnamon; compress;

https://doi.org/10.33860/mnj.v1i1.268

\section{PENDAHULUAN}

Gout Arthitis merupakan pembentukan kristal pada persendian, akibat tingginya kadar asam urat dalam darah. Penumpukan kristal tersebut mengakibatkan kerusakan pada daerah persendian sehingga dapat menimbulkan nyeri. ${ }^{1}$ Gout Arthitis banyak di derita oleh lansia berkaitan dengan proses penuaan. $^{2}$

Menurut World Health Organization, prevalensi Gout Arthitis di dunia sebanyak 34,2\%. ${ }^{3}$ Prevalensi Gout Arthitis di Indonesia pada tahun 2013 sebesar
$11,4 \%$, pada tahun 2018, preverensi penyakit sendi pada lansia di Sulawesi Tengah sebanyak 7,72\%, ${ }^{4}$ Kabupaten Poso jumlah penderita Gout Arthritis sebanyak 2.112 penderita. Terbanyak terdapat di Puskesmas Mapane, Kecematan Poso Pesisir. ${ }^{5}$ Pada tahun 2017 jumlah penderita Gout Arthitis di Puskesmas Mapane sebanyak 613 dan meningkat pada menjadi 652 penderita tahun $2018 .^{6}$ Kelurahan Kasiguncu, terdapat 22 penderita. $^{6}$

Salah satu intervensi Keperawatan komplementer yang dapat dilakukan secara mandiri 
oleh perawat dalam mengontrol nyeri pasien gout artritis adalah menggunakan kompres kayu manis. Penelitian Sri Margowati dan Sigit Priyanto (2017) mengemukakan bahwa intervensi kompres kayu manis sangat berpengaruh terhadap penurunan skala nyeri pada pederita Gout Arthitis. ${ }^{7}$

Berdasarkan latar belakang ini, maka peneliti tertarik untuk melihat "Penerapan Kompres Kayu Manis (Cinnamomum Burmani) terhadap Penurunan Nyeri pada Asuhan Keperawatan Gerontik pada Pasien dengan kasus Gout Arthritis di Kelurahan Kasiguncu Wilayah kerja Puskesmas Mapane.

\section{METODE PENELITIAN}

Penelitian ini dengan pendekatan tudi kasus untuk mendapatkan gambaran Penerapan Kompres Kayu Manis terhadap Nyeri pada Asuhan Keperawatan Gerontik pada pasien kasus Gout Arthitis. Bertempat di Desa Petirobajo di Kelurahan Kasiguncu Wilayah kerja Puskesmas Mapane, selama 6 hari. Subyek penelitian adalah satu orang pasien lansia penderita Gout Arthritis yang mengalami Nyeri. Data dikumpulkan dengan menggunakan format pengkajian gerontik melalui wawancara, observasi, prioritas masalah keperawatan, dan intervensi berdasarkan Eviden Based Nurse tentang pengaruh penggunaan kompres kayu manis terhadap nyeri Gout Arthitis.

\section{HASIL PENELITIAN}

Setelah dilakukan pengajian keperawatan didapatkan klien pendidikan SD, beragama islam, status janda, TB $160 \mathrm{~cm}$, BB $64 \mathrm{~kg}$, beralamat di desa petirobajo Kelurahan Kasiguncu. Data subjek: Ny.N mengatakan nyeri timbul pada saat mengkonsumsi makanan seperti kacang-kacangan, sayur yang bersantan, dan duduk dengan kaki terlipat terlalu lama, nyeri yang dirasakan pada daerah lutut dan pergelangan kaki, seperti tertusuk - tusuk, tidak menyebar, susah untuk berjalan, sudah 1 tahun mengeluh nyeri di bagian lutut, 3 hari sebelum penyakit kambuh ia mengomsumsi kacang-kacangan dan sayur yang bersantan.

Data Objektif: Kesadaran composmentis, Tekanan darah 140/80 mmHg, Nadi $80 \mathrm{x} / \mathrm{mnt}$, Respirasi 20x/mnt, Suhu $36,3^{\circ} \mathrm{C}$, Skala nyeri 6, Kadar asam urat $10,3 \mathrm{mg} / \mathrm{dL}$, perubahan dalam cara berjalan yaitu dengan langka kecil, terdapat nyeri tekan pada lutut, dan pergelangan kaki, ekspresi wajah nampak meringis, kesulitan dalam membolakbalik posisi tubuh, ketidakstabilan postur tubuh saat melakukan rutinitas yaitu pekerjaan rumah tangga.

Diagnosa keperawatan: Nyeri akut berhubungan dengan agen-agen penyebab cidera biologis (inflamasi sendi), Di tandai dengan : Ny.N mengatakan nyeri timbul pada saat mengkonsumsi makanan seperti kacang-kacangan, sayur yang bersantan dan duduk dengan kaki terlipat terlalu lama, Ny. N mengatakan nyeri yang dirasakan pada daerah lutut dan pergelangan kaki, tidak menyebar, Ny.N mengatakan susah untuk berjalan, Ny. N mengatakan tidak tahu soal penyakit yang di deritanya, Nyeri di rasakan seperti tertusuk-tusuk, dan Data Objektifnya: TD: 140/80 $\mathrm{mmHg}$, N: 80 $\mathrm{x} / \mathrm{mnt}, \mathrm{R}: 20 \mathrm{x} / \mathrm{mnt}, \mathrm{S}: 36,3^{\circ} \mathrm{C}$, skala nyeri 6 , terdapat nyeri pada bagian lutut dan pergelangan kaki sebelah kiri, Muka nampak meringis, Kadar asam urat 10,3 $\mathrm{m} / \mathrm{dL}$.

Intervensi keperawatan: Lakukan pengkajian nyeri komprehensif yang meliputi lokasi, karekteristik, durasi, frekuensi, kualitas, intensitas, atau beratnya nyeri dan faktor pencetus, Gunakan komunikasi terapeutik agar klien dapat mengekspresikan nyeri, Ajarkan penggunaan teknik kompres kayu manis. Ajarkan prinsip-prinsip manajemen nyeri, Lakukan pemeriksaan kadar asam urat, Kurangi atau eliminasi faktor-faktor yang dapat mencetuskan atau meningkatkan nyeri (misalnya, ketakutan, kelelahan, keadaan monoton, dan kurang pengetahuan), Dukung istrahat/tidur yang adekuat untuk membantu penurunan nyeri, Evaluasi keefektifan dan tindakan mengontrol nyeri.

Implementasi: Setelah di lakukan tindakan keperawatan selama 4 kali kunjungan di harapkan tingkat nyeri menurun dari skala 6 ke skala 3, dengan kriteria hasil: Klien melaporkan nyeri dan pengaruhnya dalam tubuh, Klien mampu mengenal skala, intensitas, frekuensi, dan lamanya periode nyeri, Klien mengatakan rasa nyaman setelah nyeri berkurang, Tanda-tada vital dalam batas normal, Ekspresi wajah tenang. Implementasi yang dilakukakan pada Hari 1: Mengkaji secara komprehensif tentang nyeri, meliputi: lokasi, karakteristik, durasi, frekuensi, kualitas, intensitas/bertanya nyeri dan faktor-faktor pencetus, Menggunakan komunikasi terapeutik agar klien dapat mengekspresikan nyeri, Melakukan pemeriksaan kadar asam urat. 
Hasil evaluasi hari 1: S: klien mengatakan nyeri di rasakan di bagian lutut dan pergelangan kaki sebelah kanan, seperti tertusuk-tusuk, di rasakan selama 10 menit, tidak menyebar. O: TD :140/80 $\mathrm{mmHg}, \mathrm{N}: 80 \mathrm{x} / \mathrm{mnt}, \mathrm{R}: 20 \mathrm{x} / \mathrm{mnt}, \mathrm{S}: 36,3^{\circ} \mathrm{C}$, Kadar asam urat $10,3 \mathrm{mg} / \mathrm{dL}$, skala nyeri 6 , terdapat nyeri tekan pada lutut dan pergelangan kaki sebelah kanan. A: masalah belum teratasi, P: lanjutkan intervensi. Implementasi hari 2: Melakukan teknik nonfarmakologi untuk mengurangi nyeri yaitu dengan teknik kompres kayu manis selama kurang lebih 1520 menit dengan dua sendok bubuk kayu manis dan air hangat secukupnya sampai berbentuk pasta, Mengajarkan prinsip-prinsip manajemen nyeri yaitu teknik relaksasi napas dalam. klien mengatakan masih merasakan nyeri di bagian lutut. Evaluasi hari 2: O: TD: $140 / 80 \mathrm{mmHg}, \mathrm{N}: 80 \mathrm{x} / \mathrm{mnt}$, R: $20 \mathrm{x} / \mathrm{mnt}$, S: $36,3^{\circ} \mathrm{C}$, skala nyeri 4 . A: masalah belum teratasi P: lanjutkan intervensi.

Implementasi hari ke 3: Melakukan teknik nonfarmakologi untuk mengurangi nyeri yaitu dengan teknik kompres kayu manis selama kurang lebih 1520 menit dengan dua sendok bubuk kayu manis dan air hangat secukupnya sampai berbentuk pasta, Mengajarkan prinsip-prinsip manajemen nyeri yaitu teknik relaksasi napas dalam, Melakukan pemeriksaan kadar asam urat. Evaluasi hari ke 3: S: klien megatakan nyeri pada bagian lututnya berkurang. O: TD: 140/80 mmHg, N: 80x/mnt, R: $20 \mathrm{x} / \mathrm{mnt}, \mathrm{S}: 36,3^{\circ} \mathrm{C}$, Kadar asam urat $8,8 \mathrm{mg} / \mathrm{dL}$, skala nyeri 3. A: masalah belum teratasi. P: lanjutkan intervensi

Implementasi hari ke 4: Melakukan teknik nonfarmakologi untuk mengurangi nyeri yaitu dengan kompres kayu manis selama kurang lebih 15-20 menit dengan dua sendok bubuk kayu manis dan air hangat secukupnya sampai berbentuk pasta, Mengajarkan prinsip-prinsip manajemen nyeri yaitu teknik relaksasi napas dalam.

Evaluasi hari ke 4: S: klien megatakan nyeri pada bagian lututnya berkurang. O: TD: $140 / 80 \mathrm{mmHg}$,

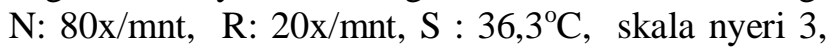
A: masalah belum teratasi P: lanjutkan intervensi

\section{PEMBAHASAN}

\section{Pengkajian}

Berdasarkan teori, manifestasi klinis yang di dapati pada penderita gout artritis adalah sendi yang terkena menjadi merah, hangat, bengkak, dan secara khas nyeri dan nyeri tekan. Sekitar 50\% serangan awal arthritis gout akut terjadi pada sendi metatarsophalangeal pada jari besar. Selain itu dapat terjadi pada punggung kaki, pergelangan kaki, tumit, lutut, pergelangan tangan, jari dan sendi. ${ }^{8}$ Jika di bandingkan dengan data yang diperoleh pada pengkajian dimana klien juga mengeluhkan nyeri pada Ny.N daerah lutut dan pergelangan kaki, seperti tertusuk-tusuk, tidak menyebar, susah untuk berjalan, Skala nyeri 6, perubahan dalam cara berjalan yaitu dengan langka kecil, terdapat nyeri tekan pada lutut, dan pergelangan kaki, ekspresi wajah nampak meringis, kesulitan dalam membolakbalik posisi tubuh, ketidakstabilan postur tubuh saat melakukan rutinitas yaitu pekerjaan rumah tangga. Ini menunjukan bahwa data yang diperoleh pada hasil pengkajian sejalan dengan teori yang menjelaskan tentang manifestasi klinis penderita gout arthritis.

\section{Diagnosa keperawatan}

Menurut Judith Wilkonson (2016). ${ }^{9}$ diagnose yang sering muncul pada klien yang menderita gout arthritis adalah nyeri akut, hambatan mobilisasi fisik, defisiensi pengetahuan dan risiko jatuh. Berdasarkan diagnosa yang di dapatkan pada Ny.N sejalan dengan teori yang ada, namun penulis hanya berfokus pada satu diagnosa prioritas yang di terapkan pada pasien yaitu nyeri akut. Nyeri sendi pada pasien Gout Arthitis terjadi karena adanya endapan kristal monosodiumurat yang terkumpul di dalam sendi sebagai akibat dari tingginya kadar asam urat di dalam darah. Bila kristal urat tertimbun pada jaringan diluar sendi akan membentuk tofi atau tofu yaitu benjolan bening di bawah kulit yang berisi kristal urat yang menyebabkan timbulnya nyeri. ${ }^{9}$

\section{Intervensi}

Hasil intervensi pemberian kompres kayu manis yang di lakukan pada klien Ny.N selama 1 minggu dengan 4 kali pemberian menunjukan perubahan yang signifikan. Klien Ny.N mengatakan sebelum di berikan kompres kayu manis klien merasakan nyeri dengan skala nyeri 6 , tetapi setelah pemberian 4 kali terapi kompres kayu manis klien merasakan nyerinya sudah berkurang dan klien bisa berjalan dengan normal, selain itu pemeriksaan kadar asam urat dari Ny.N yang pertama nya $10,3 \mathrm{gr} / \mathrm{dL}$ selama 4 kali pemberian terapi kompres kayu manis sudah berangsur-angsur turun menjadi 6,3 gr/dL. Sebelumnya klien jarang atau bahkan belum pernah 
melakukan terapi pengobatan nyeri sendi Gout Arthritis dengan pengobatan kompres kayu manis. Klien hanya mengandalkan obat-obatan medis seperti allopurinol. Intensitas nyeri klien menurun karna efek kompres kayu manis dapat merelaksasikan otot, menghambat terjadinya inflamasi, memberi perasaan nyaman, merangsang pengeluaran endhorpins dan antirematik.

Kayu manis mengandung bermacam-macam bahan yaitu minyak atsiri (1-4\%) yang berisi sinamaldehid (60-80\%), eugenol (sampai 10\%) dan trans asam sinnamat (5-10\%, senyawa fenol (410\%), tannin, katechin, proanthocyanidin, monoterpen, dan sesquiterpen (pinene), kalsium monoterpen oksalat, gum getah, resin, pati, gula, dan coumarin dan Kayu manis juga mempunyai kandungan kimia yang sangat berperan sebagai anti rematik dan antiiflamasi. ${ }^{8}$

Kompres dengan menggunakan air hangat mengakibatkan terjadinya vasodilatasi pembuluh darah sehingga akan meningkatkan relaksasi otot dan mengurangi nyeri akibat spasme atau kekakuan, dan juga memberikan rasa yang nyaman. ${ }^{10}$ Penambahan kayu manis dalam air hangat lebih mendorong terjadinya penurunan nyeri sebab kayu manis mengandung anti inflamasi dan anti remmatik yang berperan dalam proses penyembuhan peradangan sendi. ${ }^{7}$ Hal ini di dukung oleh penelitian Sri dan Sigit (2017), yang mengambil penderita yang berusia 60 tahun, yang berjenis kelamin perempuan. Hal ini dikerenakan perempuan telah mengalami menopause. Perempuan yang mengalami menopause hormone ektrogennya menurun, sehingga tidak dapat mengontrol pembungan asam urat. ${ }^{7}$ Penderita yang mengalami Gout Terdapat penurunan skala nyeri pada penderita Gout Arthitis secara signifikan, artinya bahwa intervensi menggunakan kompres kayu manis lebih memberi efek terhadap penurunan nyeri Gout atrhitis.

\section{Implementasi}

Implementasi yang dilakukan selama 4 hari berfokus pada implementasi untuk mengatasi masalah keperawatan yaitu nyeri. Berdasarkan perencanaan intervensi (NIC), ${ }^{11}$ ada banyak hal yang dapat dilakukan dalam manajemen nyeri. Akan tetapi pada penelitian ini, peneliti lebih memfokuskan implementasi keperawatan berupa pemberian terapi komplementer kompres kayu manis untuk menurunkan nyeri. Hal ini mengingat focus studi dalam penelitian ini adalah untuk melihat penerapan kompres kayu manis untuk menurunkan nyeri. Implementasi yang dilakukan selama 4 hari, menunjukan penurunan skala nyeri secara bertahap. Hal ini sangat nampak pada hari ke 3 dimana skala nyeri menurun secara signifikan dari 6 (nyeri sedang) menjadi 3 (nyeri ringan).

\section{Evaluasi}

Berdasarkan hasil evaluasi yang dilakukan oleh perawat setiap hari setelah melakukan implementasi, dapat di lihat bahwa skala nyeri menurun secara bertahap setiap harinya. Pada hari 1 skala nyeri 6 (Sedang). Hasil evaluasi yang dilakakukan pada hari terakhir (hari ke 4) menunjukan bahwa skala nyeri menjadi 3 (ringan). Dapat disimpulkan bahwa masalah teratasi sebagian dan perlu dipertahankan intervensi.

\section{SIMPULAN DAN SARAN}

Pemberian kompres kayu manis 4 kali pemberian selama 1 minggu dapat menurunkan nyeri dari skala nyeri 6 (sedang) menjadi 3 (nyeri ringan).

Saran: Klien dapat menggunakan terapi kompres Kayu Manis sebagai salah satu alternative penanganan non farmakologis yang murah, mudah dan dapat dilakukan secara mandiri oleh klien maupun keluarga di rumah.Perawat dapat mengembangkan dan meneliti lebih lanjut terapi komplementer kompres kayu manis sebagai salah satu alternative manajemen nyeri.

\section{DAFTAR PUSTAKA}

1. Siregar Munawaroh. Pengaruh Penggunaan Kompres Kayu Manis (Cinnamomum Burmani)Terhadap Penurunan Nyeri Penderita Arthitis Gout. OM FKp. 2018; Vol. 5 No.

2. Kholifah Nur Siti. Keperawatan Gerontik. Jakarta Selatan. Jakarta: EGC; 2016.

3. Word Health Organisation. WHO methods and data sources global burden of diasese estimates 2000-2015. 2017.

4. Kementrian Kesehatan Republik Indonesia Badan Penelitian dan Pengembangan Ksehatan. Laporan Riset Kesehatan Dasar 2018. Jakarta;

5. Dinkes Kab. Poso. Profil Dinas Kesehatan Kabupaten Poso. Poso; 2018.

6. Mapane P. Profil Puskesmas Mapane. Poso; 2018. 
7. Margowati Sri \& Priyanto Sigit. Pengaruh Penggunaan Kompres Kayu Manis (Cinnamomum Burmani) Terhadap Penurunan Nyeri Penderita Arthitis Gout. 2017;

8. Chang Esther D. Patofisiologi Aplikasi pada Praktik Keperawatan. Jakarta; 2009.

9. Wilkinson Judith M. Diagnosis keperawatan. Jakarta: EGC; 2016.

10. Herlina dkk. Latihan Range of Motion Berpengaruh terhadap Mobilitas Fisik pada Lansia di Balai Pelayanan Sosial Tresna Werdha
Unit Abiyoso Yogyakarta Jurnal Ners dan Kebidanan Indonesia. JNKI [Internet]. 2016; Available from: http://ejournal.almaata.ac.id/index.php/JNKI

11. Nurarif Huda Amin \& Kusuma Hardhi. Aplikasi Asuhan Keperawatan Berdasarkan Diagnosa dan Nanda Nic-Noc jilid 2. 2nd ed. Yogyakarta: Mediaction; 2015. 